\title{
Physical activity practice and sports preferences in a group of Spanish schoolchildren depending on sex and parental care: a gender perspective
}

África Peral-Suárez ${ }^{1 *}$ D , Esther Cuadrado-Soto ${ }^{1}$, José Miguel Perea ${ }^{2,3}$, Beatriz Navia ${ }^{1,3}$, Ana M. López-Sobaler ${ }^{1,3}$ and Rosa M. Ortega ${ }^{1,3}$

\begin{abstract}
Background: Physical activity plays an important role in the maintenance of health, and it is especially important during childhood. However, the lack of information about differences in physical activity practice and sports preferences of children considering gender differences can result in non-effective policies that enhance inequalities between sexes. The aim of this study is to identify the sports preferences of Spanish schoolchildren and their physical activity practice behaviors depending on their sex and their parental care, analyzing the possible differences from a gender perspective.

Method: Three hundred sixty-four Spanish schoolchildren (179 girls, 185 boys) participated in this cross-sectional study. A daily physical activity questionnaire was used to evaluate physical activity level (PAL), moderate-to-vigorous physical activity (MVPA) and sports preferences and a socio-health questionnaire were used to collect data about parental care. Statistical analysis was performed using SPSS and applying Student's T-test for normal variables, Mann-Whitney U-test for non-parametrical variables, and chi-square (x2) test for categorical variables. Subsequently, odds ratios were used to analyze associations between the physical activity practice of the children and parental care.

Results: PAL and time spent in MVPA was significantly lower for girls compared to boys ( $1.44 \pm 0.07$ vs. $1.46 \pm 0.07$, $p<0.001$ and $0.74 \pm 0.40 \mathrm{~h} /$ day vs. $0.90 \pm 0.45 \mathrm{~h} /$ day; $p<0.001$, respectively). Dancing, rhythmic gymnastics, skating, and water sports were practiced more by girls, while football, wrestling sports, handball, and racket sports were practiced more by boys $(p<0.05)$. Children cared for by their fathers had higher odds for physical activity practice $(\mathrm{OR}=1.995(1.202-3.310), p=0.008)$.

Conclusion: Physical activity among girls was less frequent and less intense. Girls opted for individual sports with artistic connotations, while boys often practiced more team contact sports. Furthermore, children are more physically actives when their father is in charge of them.
\end{abstract}

Keywords: Physical activity, Sport preferences, Schoolchildren, Sex differences, Gender, Parental influence

* Correspondence: africper@ucm.es

1 Department of Nutrition and Food Science, Faculty of Pharmacy at

Universidad Complutense de Madrid, Madrid, Spain

Full list of author information is available at the end of the article

C C The Author(s). 2020 Open Access This article is licensed under a Creative Commons Attribution 4.0 International License, which permits use, sharing, adaptation, distribution and reproduction in any medium or format, as long as you give appropriate credit to the original author(s) and the source, provide a link to the Creative Commons licence, and indicate if changes were made. The images or other third party material in this article are included in the article's Creative Commons licence, unless indicated otherwise in a credit line to the material. If material is not included in the article's Creative Commons licence and your intended use is not permitted by statutory regulation or exceeds the permitted use, you will need to obtain permission directly from the copyright holder. To view a copy of this licence, visit http://creativecommons.org/licenses/by/4.0/. The Creative Commons Public Domain Dedication waiver (http://creativecommons.org/publicdomain/zero/1.0/) applies to the data made available in this article, unless otherwise stated in a credit line to the data. 


\section{Introduction}

Regular physical activity has numerous benefits for both physical and mental health, including the prevention of being overweight or obese, and the risk of chronic diseases (cardiovascular, diabetes, cancer, etc.), as well as reduced levels of stress and anxiety, impacting on psychological wellbeing and quality of life $[1,2]$. Furthermore, in the case of schoolchildren, physical activity has been positively associated with academic performance [3]. Physical inactivity is related to greater risk of diseases and various physiological and psychological problems, being identified as the fourth highest risk factor for mortality worldwide [1, 4].

In this context, physical activity and sports practice tend to be different between boys and girls, being lower in the case of girls, both in terms of frequency and intensity, independent of their level of education $[5,6]$.

Among possible barriers that girls face when engaging in physical activity and sports are the gender stereotypes associated with physical activity due to the masculine image it projects. This can lead to a refusal to participate in "male sports" for parts of the female population $[7,8]$. Increased difficulty achieving required goals generates huge pressure for females [9]. These gender roles are assumed from an early age [7].

The results from various past studies show that girls tend to prefer activities related to body shape and health with a more aesthetic orientation, preferring individual sports, while boys tend to opt for activities focused on improving fitness or physical performance, choosing team sports in which strength and competitiveness predominate $[10,11]$.

Several studies have shown that practice of physical activity by parents or parental support in this area may improve physical activity by the children. However, the difference between maternal and paternal influence is not clear. In some studies, it was observed that both figures have equal influence. While in others, it was indicated that the figure that shares the sex of the schoolchild has more influence, or that the paternal figure is the most influential [12-15].

Most research on the practice of physical activity by schoolchildren focuses on time or on active transportation, ignoring the preferences of children for particular sports or types of activity. Researching these factors could improve our understanding of the reasons why they enjoy said preferences [16].

The aim of this study was to determine the differences in sports preferences of schoolchildren, as well as their practice of physical activity depending on their sex, in addition to investigating the influence children's parents or guardians in their activeness. We analyze all these factors from a gender perspective.

\section{Materials and methods}

The study design and methodology have been previously described [17-19]. The study was conducted in accordance with the Declaration of Helsinki, and the protocol was approved by the Ethics Committee for Clinic Review of the Clinic San Carlos Hospital, which is part of the Universidad Complutense de Madrid (Madrid, Spain) (Ref 12/319-E and 15/522-E). The trial was registered at clinicaltrials.gov as NCT03465657.

In brief, a cross-sectional observational study was carried out between February 2014 and February 2018 in 11 randomly contacted schools from different Spanish provinces, with representation from urban and semiurban areas, in which 367 participated healthy children aged between 7 and 11 years. The obtaining of the sample and methodology used to collect the different data is deeply described below.

\section{Subjects}

Participation in this study was offered to twenty-six randomly-contacted primary schools. Eleven schools from six different Spanish provinces (Madrid, Zaragoza, Segovia, Córdoba, Ciudad Real and Tenerife) took part in the project, of which five were in the capitals of the provinces involved and six in a semi-urban area (less than 50,000 inhabitants). Of the 1806 children who were contacted to participate, a sample of 367 children was recruited to the trial, (182 girls, 185 boys) (Fig. 1).

Each school was contacted by telephone. Once the schools Directors had accepted the invitation to participate, parents of children aged between 7 and 11 years received a letter explaining the study in detail and were given an informed consent form to fill out, as to whether they agreed with the participation of their child. Afterwards, a member of the research group met the parents who accepted the participation of their children in the study at their child's schools. This was to discuss any doubt about the trial and collect the signed informed consent forms. In said initial meeting, the member of the research group provides parents with the questionnaires to complete. Five days after the meeting, the researchers went to the school to carry out the anthropometric measurements and collect completed questionnaires.

The exclusion criteria were: a lack of signed informed consent, having an illness or physical impairment that could alter the results (serious infection or metabolic or chronic diseases as diabetes mellitus, hepatic or kidney disease), having have had surgery in the 6 months prior to the study and lack of completed questionnaires.

Children whose questionnaires had missing answers for isolated questions were excluded from the analysis of those particular questions but not from the whole study.

\section{Anthropometric and Sociodemographic data}

All anthropometric measurements were taken in the morning and in accordance with the WHO criteria [20], namely the children being barefoot and wearing just their underwear. The children entered in small groups 


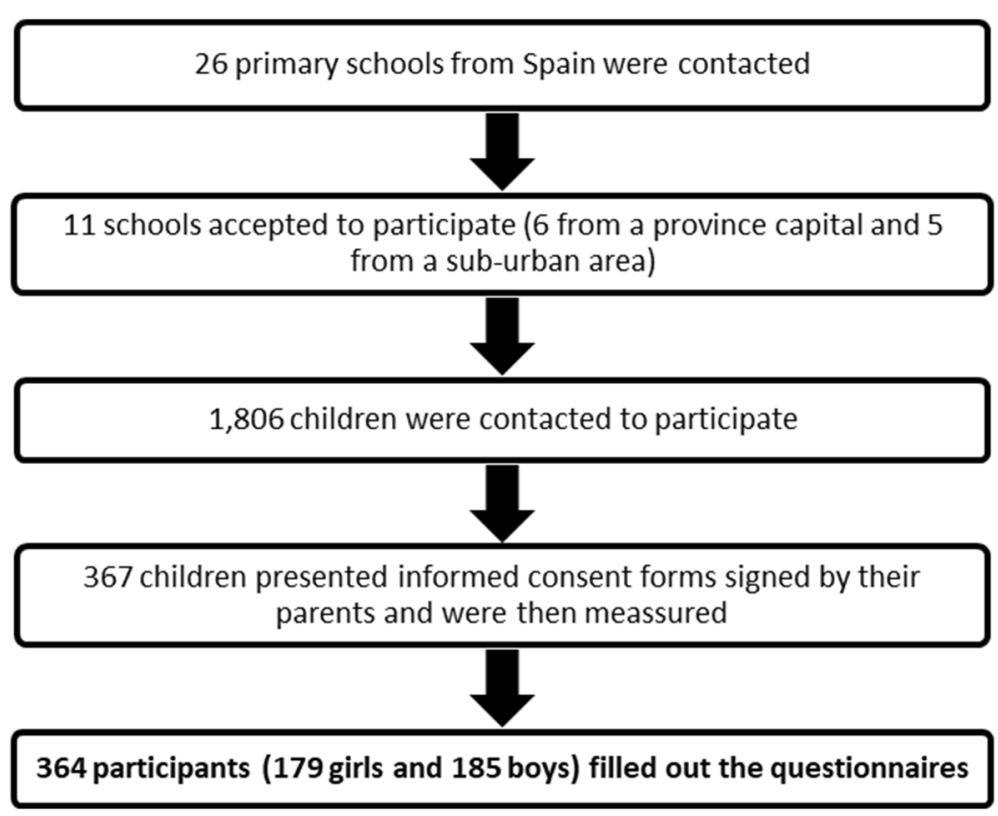

Fig. 1 Obtaining the sample

of approximately 5 children into the room where the measurements were being taken and were measured one by one in a space separated from the rest of the room by folding screens by two researchers. One of the researchers was in charge of taking the measurements and the other was in charge of noting the results.

Data about weight and height were determined using a digital electronic scale (range $0.1-150 \mathrm{~kg}$; precision 100 g; Alpha; Seca, Igni, France) and a digital stadiometer (70-205 cm; $1 \mathrm{~mm}$; Harpenden Pfifter, Carlstadt, NJ, USA) respectively. The body mass index (BMI) was calculated from these measures.

Weight status was determined using BMI specific percentiles for age and sex in the reference population following the criteria stablished by the International Obesity Task Force (IOTF) [21].

Waist circumference was measured using a flexible metallic tape (range $0-150 \mathrm{~cm}$; precision $1 \mathrm{~mm}$; Holtain, Crymych, Wales). The measurement was taken midway between the inferior margin of the last rib and the crest of the ileum, in the horizontal plane.

To obtain the sociodemographic data, we used a questionnaire about their social, economic, and health status [see Additional File 1], which were completed by their parents. This questionnaire included data on the children's caregivers, including the academic level of their parents and the household incomes.

\section{Physical activity data}

An adapted physical activity daily questionnaire [22] [see Additional File 2], which has been previously used in other studies [23-25], was filled out by the parents about their children. Questions find the time spent during weekdays and weekends in different kind of physical activities (including active play and extracurricular sport classes, physical education and daily life activities) and sedentary behaviors (including watching TV, playing videogames, tablet or computer use). Furthermore, questions were included about the kinds of sports practiced during extracurricular sporting classes, including the number of days per week and the time per session dedicated to each extracurricular sport class.

After collecting the information, individual physical activity levels (PAL) were calculated by multiplying the time in hours spent on each group of activities with their assigned coefficient depending on their intensity (1.0 for rest, 1.5 for very low-intensity PA, 2.5 for low-intensity PA, 5.0 for moderate-intensity PA and 7.0 for very highintensity PA) following the WHO criteria [26]. Additionally, the reported mean of moderate to vigorous physical activity (MVPA) hours per day was quantified, considering those activities with the assigned factors 5 or 7 [26], which included: physical education in school and extracurricular physical activities. The reported mean of sedentary leisure hours per week was computed, considering the use of electronic displays (computer, videogame console, tablet, and TV). This data was used to estimate adherence to the recommendations of physical activity ( $\geq 60 \mathrm{~min}$ MVPA per day) and screen time ( $\leq 2 \mathrm{~h}$ per day) contained in the guidelines [27, 28].

We also classified children as non-sedentary when their PAL was 1.4 or higher [29]. 


\section{Statistical analysis}

All the results were analyzed using the IBM SPSS Inc. statistical software (version 25.0) and they were shown as mean \pm standard deviation (SD), medians, and interquartile range (IQR) or as proportions if variables were categorical. The Kolmogorov-Smirnov test was used to assess the normality of the variables. To compare data between sexes, we used the Student's two sample t-test (in cases of normal variables), Mann-Whitney U-test (in cases of non-parametrical variables), and $\chi^{2}$ test for categorical variables.

Subsequently, logistic regression models were used to analyze the possible association between physical activity of the children (dependent variable) and the person who takes care of them (independent variables), using as reference for physical activity practice: PAL $\geq 1.4$, according to National Academy of Medicine (NAM) cut-off points, previously known as Institute of Medicine (IOM) [29]. This association was evaluated by 3 models of the odds ratio (OR) using 95\% confidence intervals (CI): (a) a basic model without any adjustment, (b) a second model taking into account sex and age, and (c) a third model including model $\mathrm{b}$ plus the rest of the predictor variables: cared by mother (yes/no), cared by father (yes/no) or cared by others (yes/no).

Differences were considered statistically significant if the $p$-value $<0.05$.

\section{Results}

From the initial sample of 367 children (182 girls and 185 boys), three girls did not answer at least one of the questionnaires, so the final sample was reduced to 364 children (179 girls and 185 boys).

The mean age of the participants was $8.98 \pm 1.21$ years. No significant differences between sexes were found analyzing anthropometric measures and sociodemographic data collected in Table 1.

\section{Physical activity and sedentary behavior according to sex} The results of Table 2 show that boys performed more $(p<0.001)$ and more intense $(p<0.001)$ physical activity than girls, spending more time on attending extracurricular sport classes $(p=0.001)$ and on active playing $(p=0.014)$.

Furthermore, adherence to physical activity guidelines is also significantly higher in case of boys $(42.0 \%$ vs. $23.46 \%$; $p<0.001)$. However, males also spent more time using electronic displays such as PCs, tablets or videogame consoles $(1.01 \pm 0.78 \mathrm{~h} /$ day vs. $0.76 \pm 0.58 \mathrm{~h} /$ day; $p<0.001)$.

Even though no significant differences among sexes were found related to adherence to sedentary guidelines, it is important to highlight that adherence to sedentary behavior recommendation was low (41.95\%), with more than a half of the study population being sedentary.
Furthermore, the percentage of the sample that adheres to physical activity guidelines is also below the half (32.7\%), being lower the adherence of girls respect to boys $(p<0.001)$.

\section{Sports preferences by sex}

Figure 2 shows that the most practiced sport was football $(n=89)$, followed by dancing $(n=68)$, water sports $(n=57)$, and basketball $(n=45)$. By contrast, the less practiced sports were golf, volleyball, and climbing $(n=$ $2)$, followed by yoga $(n=4)$. Comparing preferences by sex, the results showed that girls were more inclined to choose dancing $(p<0.001)$, rhythm gymnastics $(p<$ $0.001)$, skating $(p=0.005)$, and water sports $(p=0.012)$, while the boys opted for football $(p<0.001)$, wrestling sports $(p<0.001)$, racket sports $(p=0.004)$, and handball $(p=0.020)$. For the rest of sports, no significant differences were found among sexes.

The percentage of non-sedentary boys (PAL $\geq 1.4$ ) was higher than the percentage of non-sedentary girls $(82.9 \%$ vs. $68.2 \% ; p=0.001)$.

Table 3 shows the association between active children (PAL $\geq 1.4$ ) and the sex of the caregiver. Children cared by their father were more likely to engage in physical activity $(\mathrm{OR}=1.995$ (1.202-3.310), $p=0.008)$, which was not seen in those cared by their mother. After adjusting for age, sex, and the rest of the predictor variables, this association was also observed in children cared by a person different from the father or the mother $(\mathrm{OR}=2.222$ (1.136-4.343), $p=0.020)$. However, it was not known if this person was a male or female figure.

\section{Discussion}

$28.02 \%$ of the total sample presented overweight and the $10.16 \%$ were obese, without significant differences among sexes. The percentage of overweight is higher than that in other studies carried out in the Spanish population, such as the ALADINO study, where in a sample of 10,899 children aged between 6 and 9 years, the percentage of overweight and obesity using the IOTF cut-off points was 21.8 and $11.2 \%$, respectively [30]. This may be due to the prepubertal adipose rebound previously described by other authors [31, 32], as our sample includes children up to 11 years old.

In our results, a higher and more intense physical activity practice by boys than by girls was appreciable, being higher their PAL $(1.46 \pm 0.07$ vs. 1.44 \pm 0.07 ; $p<0.001)$ the time spent in MVPA $(0.90 \pm 0.45 \mathrm{~h} /$ day vs. $0.74 \pm 0.40 \mathrm{~h} /$ day; $p<0.001$ ) (Table 2) and their adherence to physical activity recommendations $(42.0 \%$ vs. $23.46 \% ; p=0.000$ ), as it occurred in other studies with schoolchildren population, such as the ANIBES study in Spain [33], the Youth Study in China [34] or the study of Williamson et al. performed in England and Scotland 
Table 1 Anthropometric and sociodemographic data of the study sample according to sex

\begin{tabular}{|c|c|c|c|c|}
\hline & Girls $(\boldsymbol{n}=179)$ & Boys $(\boldsymbol{n}=185)$ & Total $(\boldsymbol{n}=364)$ & \\
\hline \multicolumn{5}{|l|}{ Anthropometric data } \\
\hline & Mean \pm SD & Mean \pm SD & Mean \pm SD & $p$ \\
\hline Age (years) ( $\dagger$ ) & $8.98 \pm 1.23$ & $8.98 \pm 1.20$ & $8.98 \pm 1.21$ & 0.916 \\
\hline Weight (kg) (†) & $35.89 \pm 9.04$ & $36.00 \pm 8.53$ & $35.95 \pm 8.77$ & 0.908 \\
\hline Height (cm) & $136.87 \pm 9.49$ & $137.89 \pm 8.29$ & $137.39 \pm 8.90$ & 0.276 \\
\hline BMI $\left(\mathbf{k g} / \mathrm{m}^{2}\right)(\dagger)$ & $18.93 \pm 3.27$ & $18.78 \pm 3.34$ & $18.85 \pm 3.30$ & 0.434 \\
\hline Waist circumference $(\mathrm{cm})(\dagger)$ & $63.77 \pm 8.18$ & $64.59 \pm 9.52$ & $64.19 \pm 8.88$ & 0.674 \\
\hline \multicolumn{5}{|l|}{ Weight status } \\
\hline & $n(\%)$ & $n(\%)$ & $n(\%)$ & $p$ \\
\hline Classification BMI (IOTF) & & & & 0.377 \\
\hline Underweight & $10(5.59)$ & $5(2.70)$ & $15(4.12)$ & \\
\hline Normal weight & $98(54.75)$ & $112(60.54)$ & $210(57.69)$ & \\
\hline Overweight & $54(30.17)$ & $48(25.95)$ & $102(28.02)$ & \\
\hline Obesity & $17(9.50)$ & $20(10.81)$ & $37(10.16)$ & \\
\hline \multicolumn{5}{|l|}{ Sociodemographic data } \\
\hline & $n(\%)$ & $n(\%)$ & $n(\%)$ & $p$ \\
\hline Academic level of father & & & & 0.200 \\
\hline No academic education & $3(1.79)$ & $2(1.12)$ & $5(1.45)$ & \\
\hline Primary school & $41(24.40)$ & $36(20.22)$ & $77(22.25)$ & \\
\hline High school/NT & $61(36.31)$ & $86(48.31)$ & $147(42.49)$ & \\
\hline University degree & $56(33.33)$ & $45(25.28)$ & $101(29.19)$ & \\
\hline Master/PhD & $6(3.57)$ & $9(5.06)$ & $15(4.34)$ & \\
\hline Academic level of mother & & & & 0.490 \\
\hline No academic education & $0(0.00)$ & $0(0.00)$ & $0(0.00)$ & \\
\hline Primary school & $34(19.10)$ & $30(16.57)$ & $64(17.83)$ & \\
\hline High school/NT & $66(37.08)$ & $79(43.65)$ & 145 (40.39) & \\
\hline University degree & $68(38.20)$ & $66(36.46)$ & $134(37.33)$ & \\
\hline Master/PhD & $10(5.62)$ & $6(3.31)$ & $16(4.46)$ & \\
\hline Household incomes & & & & 0.225 \\
\hline Less than $12,000 € /$ year & $18(11.8)$ & $20(12.7)$ & $38(12.3)$ & \\
\hline $12,000 €-30,000 € /$ year & $56(36.6)$ & $74(47.1)$ & $130(41.9)$ & \\
\hline $30,001 €-48,000 € /$ year & $42(27.5)$ & $33(21.0)$ & $75(24.2)$ & \\
\hline More than $48,000 € /$ year & $37(24.2)$ & $30(19.1)$ & $67(21.6)$ & \\
\hline Habitat & & & & 0.734 \\
\hline Province capital & $98(54.75)$ & $98(52.97)$ & $196(53.85)$ & \\
\hline Semi-urban area & $81(45.25)$ & $87(47.03)$ & $168(46.15)$ & \\
\hline Children care & & & & 0.088 \\
\hline Mother & $60(33.52)$ & $62(33.88)$ & $122(33.70)$ & \\
\hline Father & $4(2.23)$ & $7(3.83)$ & $11(3.04)$ & \\
\hline Another person & $10(5.59)$ & $7(3.83)$ & $17(4.70)$ & \\
\hline Mother + Father & $59(32.96)$ & $81(44.26)$ & $140(38.67)$ & \\
\hline Mother + Other & $21(11.73)$ & $14(7.65)$ & $35(9.67)$ & \\
\hline Father + Other & $1(0.56)$ & $1(0.55)$ & $2(0.55)$ & \\
\hline Mother + Father + Other & $24(13.41)$ & $11(6.01)$ & $35(9.67)$ & \\
\hline
\end{tabular}

SD Standard deviation; BMI Body mass index; VT Vocational Training. †: $p$-value calculated by Mann-Whitney U-test 
Table $\mathbf{2}$ Differences in physical activity practice based on sex

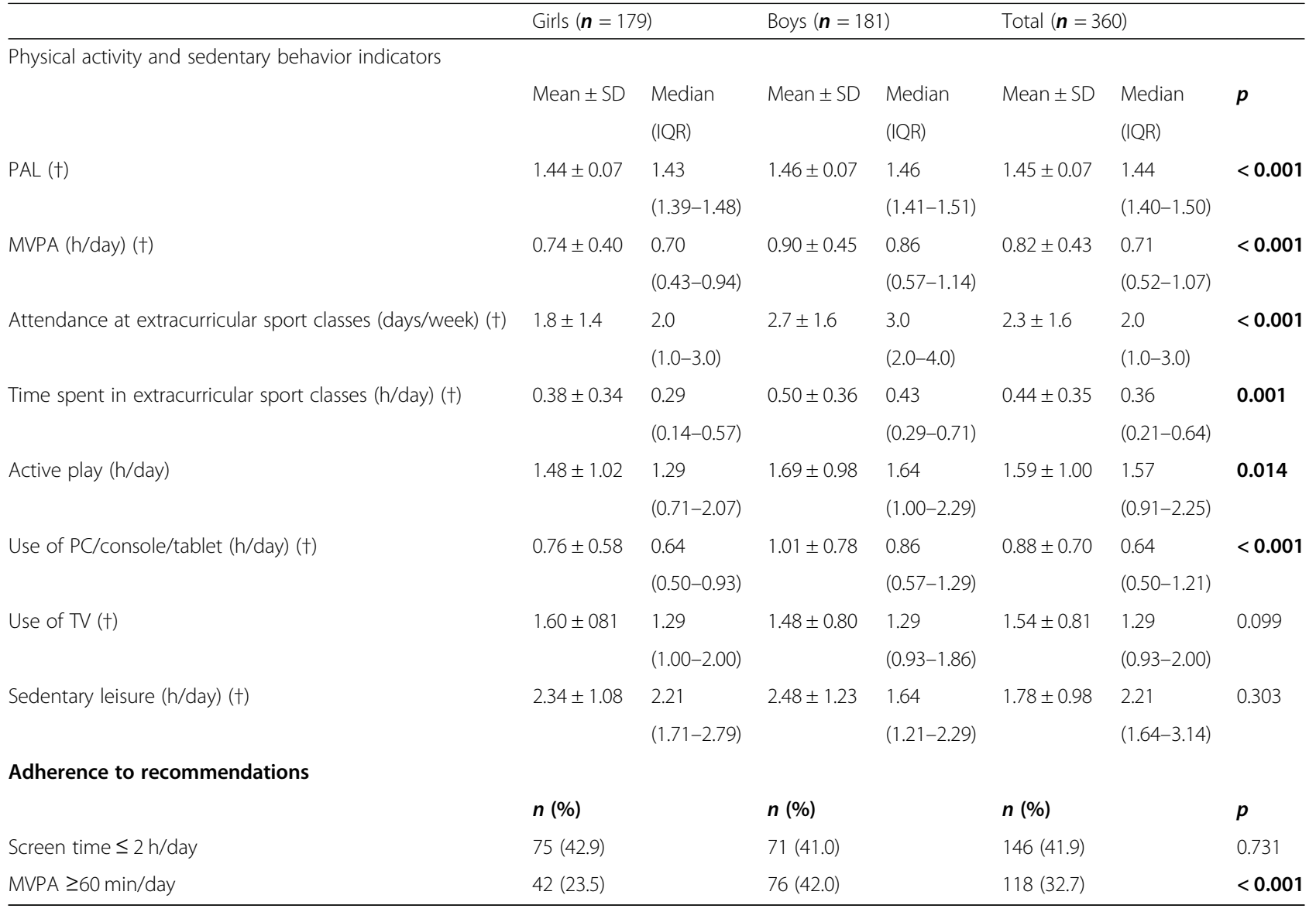

SD Standard deviation; IQR Interquartile range; PAL Physical activity level; MVPA Moderate to vigorous physical activity. Significant differences according to sex $(p<0.05)$ are marked as bold.

t: $p$-value calculated by Mann-Whitney U-test.

[35]. A possible explanation to this situation is that during school breaks or after-school day care, boys usually take advantage of this time to practice sports, while girls use this time in sedentary activities focused on socialization [36-38]. This is reflected, too, in the differences found among sexes when time dedicated to active play was analyzed, as boys spent more time on active play than girls $(p=0.014)$, which is partly attributable to the poor distribution of space in school playgrounds or sports facilities, as it does not take into account different sporting preferences, to the prejudice of those children who do not use material like football goal posts or basketball nets, who are generally girls [37, 39]. Related to these findings, we saw that boys also attended extracurricular sport classes more frequently and for more hours than girls $(2.7 \pm 1.6$ days/week vs. $1.8 \pm 1.4$ days/week; $p<0.001$ and $0.50 \pm 0.36 \mathrm{~h} /$ day vs. $0.38 \pm 0.34 \mathrm{~h} /$ day; $p=$ 0.001 , respectively) (Table 2). These kinds of differences are similar to those observed in the ALADINO study [30], where boys also spent more time in the practice of extracurricular sport activities than girls.
The mean time spent in sedentary leisure activities was $2.34 \pm 1.08 \mathrm{~h}$ by girls and $2.48 \pm 1.23 \mathrm{~h}$ by boys, being found significant differences between sexes only when time spent using PCs, tablets or game stations was analyzed, being higher the time dedicated by boys to this kind of activity $(p<0.001)$. Other studies showed this higher time spent by boys in recreational use of computers or other electronic devices [40], even though girls usually spent more time in sedentary behaviors [41].

Regarding sports preferences collected in Fig. 2, the data showed that children tend to choose activities in line with their gender roles, with a higher female participation in sports socially perceived as feminine, like dancing $(94.1 \%$ girls vs. $5.9 \%$ boys; $p<0.001)$ or rhythmic gymnastics $(93.1 \%$ girls vs. $6.9 \%$ boys; $p<0.001)$, while males participated more in sports socially perceived as masculine, like football $(97.8 \%$ boys vs. $2.2 \%$ girls; $p<$ $0.001)$ or wrestling sports $(85.7 \%$ boys vs. $14.3 \%$ girls; $p<0.001)$ [42, 43]. Furthermore, girls also participated more than boys in skating ( $80 \%$ girls vs. $20 \%$ boys; $p=$ 0.005 ) and water sports (64.9\% girls vs. $35.1 \%$ boys; $p=$ 


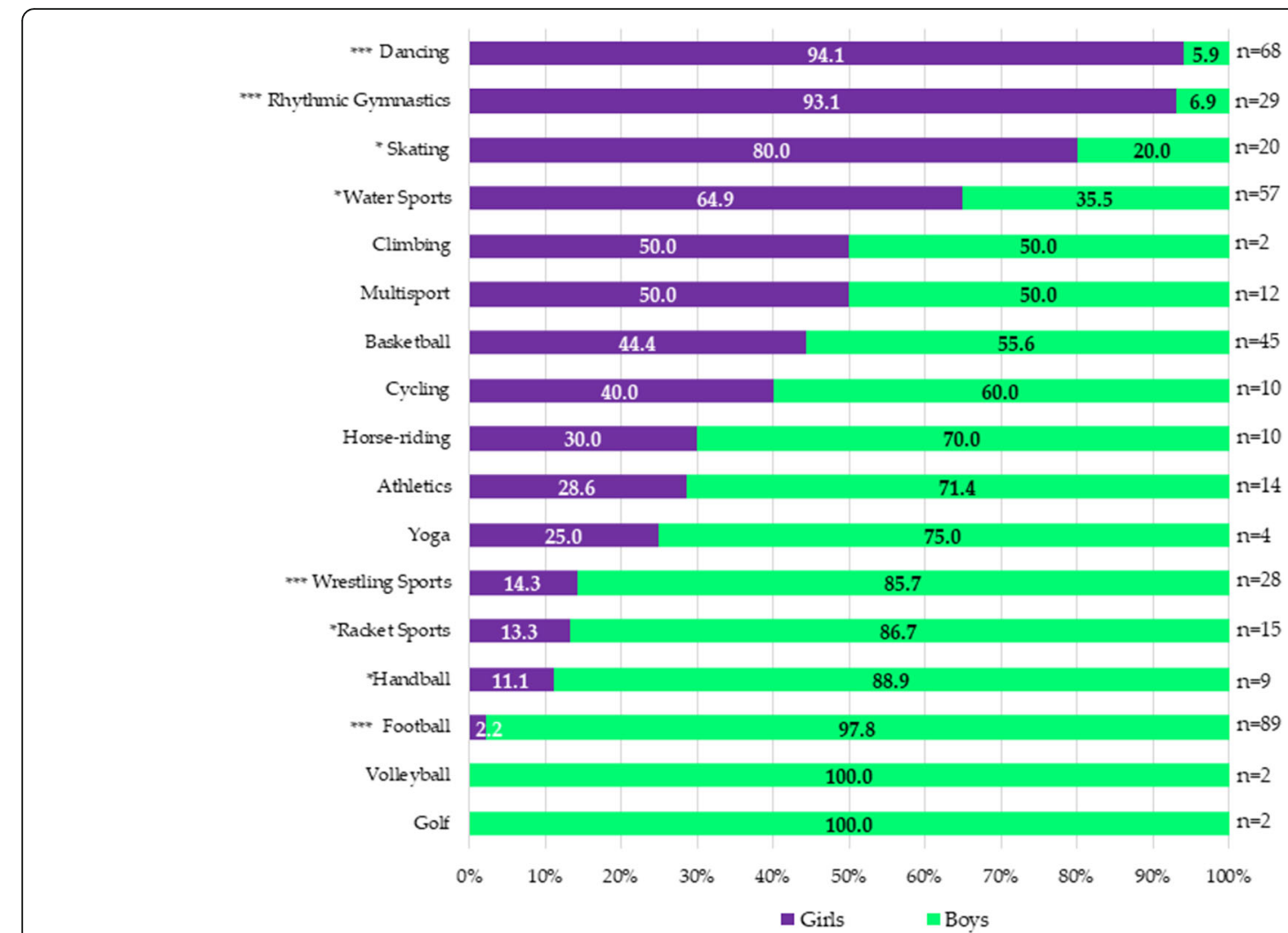

Fig. 2 Sports preferences depending on sex. ${ }^{*} p<0.05{ }^{* * *} p<0.001$. a) $p$-value represents differences among sexes

$0.012)$, and boys enrolled more in handball ( $88.9 \%$ boys vs. $11.1 \%$ girls; $p=0.02)$ and racket sports $(86.7 \%$ boys vs. $13.3 \%$ girls; $p=0.004$ ), which is in line with the literature previously mentioned, where a greater tendency of boys to practice team sports was reflected in contrast to girls, who tended to practice individual ones $[10,11,44]$. These results are similar to those found in other studies that analyzed children's sports preferences [16, 45, 46] and seem to remain true throughout life [47]. Sports segregation according to gender roles may be related to the fear of being judged or bullied if gender norms are not conformed to $[37,48]$. In fact, various articles have shown that girls are more likely to engage in team sports when other girls are playing but not when boys are playing, because boys may exclude girls when they try to participate in sports in which girls are not socially considered good enough [49-51].

Another relevant aspect of this research is the association between parental care and the practice of physical activity by the child shown in Table 3 . In relation to this, children are significantly at higher odds of engaging in physical activity when the father takes care of them $(p=$ 0.008 ), an association not seen in mother care. Nevertheless, disparities have been found in the literature in this

Table 3 Odds ratios and 95\% confidence intervals for the practice of physical activity (PAL $\geq 1.4)$ depending on the person in charge of the child's care

\begin{tabular}{|c|c|c|c|c|c|c|c|c|c|c|}
\hline \multirow{2}{*}{$\begin{array}{l}\text { Predictor Variables } \\
\text { Questions }\end{array}$} & \multirow[b]{2}{*}{ Groups } & \multicolumn{3}{|c|}{ Model 1} & \multicolumn{3}{|c|}{ Model 2} & \multicolumn{3}{|c|}{ Model 3} \\
\hline & & $\mathrm{OR}$ & Cl 95\% & $p$ & OR & Cl 95\% & $p$ & OR & Cl 95\% & $P$ \\
\hline \multirow{2}{*}{$\begin{array}{l}\text { The father takes care of the child } \\
(n=185)\end{array}$} & No & 1 & & - & 1 & & - & 1 & & - \\
\hline & Yes & 1.918 & $1.176-3.129$ & 0.009 & 1.873 & $1.140-3.078$ & 0.013 & 1.995 & $1.202-3.310$ & 0.008 \\
\hline \multirow{2}{*}{$\begin{array}{l}\text { The mother takes care of the child } \\
(n=332)\end{array}$} & No & 1 & & - & 1 & & - & 1 & & - \\
\hline & Yes & 1.615 & $0.726-3.597$ & 0.240 & 1.637 & $0.725-3.700$ & 0.236 & 2.187 & $0.914-5.231$ & 0.079 \\
\hline \multirow{2}{*}{$\begin{array}{l}\text { Other person takes care of the child } \\
(n=89)\end{array}$} & No & 1 & & - & 1 & & - & 1 & & - \\
\hline & Yes & 1.420 & $0.783-2.575$ & 0.249 & 1.718 & $0.929-3.176$ & 0.084 & 2.222 & $1.136-4.343$ & 0.020 \\
\hline
\end{tabular}

Model 1: Not adjusted; Model 2: Adjusted by sex and age; Model 3: Adjusted by sex, age, and the other predictor variables. Significant differences according to sex $(p<0.05)$ are marked as bold. 
respect. For example, the results described by Rodrigues et al. [15], as well as those described by Fuemmeler et al. [52], showed that children were more likely to engage in physical activity if both parents or the parent who shared sex with them was active, whereas other studies revealed results more similar to those found in our research, showing a greater relationship between the physical activity of the child and the influence of the father [53, 54]. This fact reinforces the theory that physical activity is culturally assumed as a masculine domain. However, it is also important to highlight the positive association with physical activity practice by children when a person different from their parents habitually takes care of them $(p=0.020)$. Although this finding differs from the previous literature [55], it can be related to time disposal by the person in charge of the care of the child, which is exploited to spend time with the child accompanying them to the park or in sports practice [56].

\section{Strengths and limitations}

The current study is one of the few to analyze the different sports preferences and parental influence on children physical activity from a gender perspective. However, there are some limitations. One of these limitations is the crosssectional design, which does not allow us to make causal inferences on the observed associations. As the study could not be carried out in all the Autonomous Communities needed, our sample is not a representative sample of the Spanish population, so the results are not representative of all the Spanish schoolchildren and they are not applicable to other age groups. Due to this low participation rate, the sample could be biased to some extent with families specially interested in their children's health, which can imply higher physical activity rates than in general population. Also, this is a secondary analysis from the project "Sodium Sources and Sodium Intake in a Representative Sample of Spanish Children", which was focused on evaluating the sodium intake of Spanish schoolchildren through 24-h urine samples. The difficulty in the collection of this measure has affected the participation in the study, so the final sample was conformed to the $20.15 \%$ of the contacted children. Furthermore, we just had the possibility to use questionnaires to collect physical activity, instead of another more objective method as accelerometer, which may lead to a bias towards underestimation or overestimation of the physical activity practice by schoolchildren. Therefore, the true associations could have been stronger or weaker than the observed associations, depending on whether the misclassification was differential or nondifferential.

\section{Conclusions}

The findings of this study indicated that girls practice less physical activity and less intensely than boys, engaging more in individual sports with artistic connotations, while boys engage more in team sports or sports with a high physical contact component.

On the other hand, when the father is in charge or takes care of the child, it is more probable that the child will be more physically active, independently of whether or not the mother is also involved in his or her care.

Considering all the above, the creation of gender policies which take into account differences in sports preferences could foster the practice of physical activity by children, especially girls, who are actually less favored in this aspect.

However, other longitudinal or intervention studies should be carried out to analyze whether these differences in sports practice between boys and girls can lead to differences in the health status of children.

\section{Supplementary information}

Supplementary information accompanies this paper at https://doi.org/10. 1186/s12887-020-02229-z.

Additional file 1. Socio-sanitary questionnaire. Questionnaire used to obtain data on the children's caregivers, including the academic level of their parents and the household incomes.

Additional file 2. Daily physical activity questionnaire. Questionnaire used to obtain data on children's physical activity, sedentary behavior and extracurricular sport classes.

\section{Abbreviations}

BMI: Body mass index; Cl: Confidence interval; IOM: Institute of Medicine; IQR: Interquartile range; MVPA: Moderate to vigorous physical activity; NAM: National Academy of Medicine; OR: Odds ratio; PAL: Physical activity level; SD: Standard deviation; VT: Vocational training; WHO: World Health Organization

\section{Acknowledgments}

Authors would like to thank the children and parents who participated in the study, as well as the schools involved for their cooperation during the entire process of data collection.

\section{Authors' contributions}

AP-S participated in research conduction and data collection, analysis and interpretation, as well as in original draft writing and formatting. EC-S participated in research conduction and data collection and analysis, as well as in the manuscript reviewing and editing. JMP participated in research conduction, data collection and original draft writing and reviewing. BN participated in research conduction, data collection and manuscript reviewing and editing. AML-S and RMO participated in research conceptualization and methodology development, funding acquisition, project administration and provision of study materials, as well as in manuscript reviewing and editing All authors read and approved the final manuscript.

\section{Funding}

This research was funded by Universidad Complutense de Madrid (UCM), through projects PR6/13-18866, GR58/08, GR3/14, GR15/17 and UCM Research Group VALORNUT-920030 thorough FEl16/127.

\section{Availability of data and materials}

The datasets generated and an alysed during the current study are not publicly available due to ethical restrictions and participant confidentiality but are available from the corresponding author on reasonable request.

Ethics approval and consent to participate

The study protocol was approved by the Ethics Committee for Clinic Review of the Clinic San Carlos Hospital, which is part of the Complutense University of Madrid (Madrid, Spain) (Ref 12/319-E and 15/522-E). The participation in 
the study was voluntary and all the participants handed an informed consent signed by their parents or guardians.

\section{Consent for publication}

Not applicable.

\section{Competing interests}

The authors declare that they have no competing interests.

\section{Author details}

'Department of Nutrition and Food Science, Faculty of Pharmacy at Universidad Complutense de Madrid, Madrid, Spain. ${ }^{2}$ Department of Nutrition, Faculty of Health Science at Universidad Alfonso X El Sabio, Villanueva de la Cañada, Madrid, Spain. ${ }^{3}$ Research Group VALORNUT-UCM (920030), Universidad Complutense de Madrid, Madrid, Spain.

Received: 3 March 2020 Accepted: 29 June 2020

Published online: 07 July 2020

\section{References}

1. Perea Sánchez JM, Aparicio Vizuete A, Mascaraque Camino M, Ortega RM. Physical and sedentary activity as modulating factors of the nutritional status. Nutr Hosp. 2015;32(Suppl 1):20-2. https://doi.org/10.3305/nh.2015.32. sup1.9473.

2. Pardo Arquero V, Jimenez Pavon D, Guillen del Castillo M, Benitez Sillero JD. Physical activity, fitness and adiposity: immigrants versus Spanish scholars. Rev Int Med y Ciencias la Act Fis y del Deport. 2013;14(54):319-38.

3. McPherson A, Mackay L, Kunkel J, Duncan S. Physical activity, cognition and academic performance: an analysis of mediating and confounding relationships in primary school children. BMC Public Health. 2018;18(1):936. https://doi.org/10.1186/s12889-018-5863-1

4. Biddle SJH, García Bengoechea E, Wiesner G. Sedentary behaviour and adiposity in youth: a systematic review of reviews and analysis of causality. Int J Behav Nutr Phys Act. 2017;14(1):1-21. https://doi.org/10.1186/s12966017-0497-8

5. Forthofer M, Dowda M, O'Neill JR, et al. Effect of child gender and psychosocial factors on physical activity from fifth to sixth grade. J Phys Act Health. 2017;14(12):953-8. https://doi.org/10.1123/jpah.2016-0487.

6. Moragón-Alcañiz F, Martínez-Bello V. Games for Girls and Games for Boys: A Study of the Representation of Children's Games Through Drawing. Rev Educ. 2016:40(1):1-17. https://doi.org/10.15517/revedu.v40i1.17439.

7. Corr M, McSharry J, Murtagh EM. Adolescent girls' perceptions of physical activity: a systematic review of qualitative studies. Am J Health Promot. 2018. https://doi.org/10.1177/0890117118818747.

8. Jun J, Kyle GT. Gender identity, leisure identity, and leisure participation. J Leis Res. 2012;44(3):353-78. https://doi.org/10.1080/00222216.2012.11950269.

9. Gil-Madrona P, Cachón-Zagalaz J, Diaz-Suarez A, Valdivia-Moral P, ZagalazSánchez ML. Girls also want to play: the joint participation of boys and girls in physical activities not organised in the school context. Movimiento. 2014; 20(1):103-24.

10. Chacón Cuberos R, Muros Molina JJ, Chacón Zagalaz J, Zagalaz Sánchez ML, Castro Sánchez M, Zurita OF. Physical activity, Mediterranean diet, aerobic capacity and motivational climate towards sport in schoolchildren in the province of Granada: a model of structural equations. Nutr Hosp. 2016;35(4): 774-81. https://doi.org/10.20960/nh.1511.

11. Martínez BV. Analysis of Body Shapes and Physical Activity Dominant Patterns in a Coloring Books Collection. Pensar en Mov Rev Ciencias del Ejerc y la Salud. 2014;12(1):1-16. https://doi.org/10.15517/PENSARMOV.V1211. 12651.

12. Schoeppe S, Liersch S, Röbl M, Krauth C, Walter U. Mothers and fathers both matter: the positive influence of parental physical activity modeling on Children's leisure-time physical activity. Pediatr Exerc Sci. 2016;28(3):466-72. https://doi.org/10.1123/pes.2015-0236.

13. Stearns JA, Rhodes R, Ball GDC, et al. A cross-sectional study of the relationship between parents' and children's physical activity. BMC Public Health. 2016;16(1):1129. https://doi.org/10.1186/s12889-016-3793-3.

14. Dominick GM, Saunders R, Kenison K. Developing scales to assess parental instrumental social support and influence on provision of social support for physical activity in children. J Phys Act Health. 2016;9(5):706-17. https://doi. org/10.1123/jpah.9.5.706.
15. Rodrigues D, Padez C, Machado-Rodrigues AM. Active parents, active children: the importance of parental organized physical activity in children's extracurricular sport participation. J Child Heal Care. 2017;22(1):159-70. https://doi.org/10.1177/1367493517741686.

16. Resaland GK, Aadland E, Andersen JR, Bartholomew JB, Anderssen SA, Moe VF. Physical activity preferences of 10-year-old children and identified activities with positive and negative associations to cardiorespiratory fitness. Acta Paediatr. 2018:1-7. https://doi.org/10.1111/apa.14487.

17. Perales-García A, Ortega RM, Urrialde R, López-Sobaler AM. Physical activity and sedentary behavior impacts on dietary water intake and hydration status in Spanish schoolchildren: a cross-sectional study. PLoS One. 2018; 13(12):e0208748. https://doi.org/10.1371/journal.pone.0208748.

18. Cuadrado-Soto E, Peral-Suarez Á, Aparicio A, Perea JM, Ortega RM, LópezSobaler AM. Sources of dietary sodium in food and beverages consumed by Spanish schoolchildren between 7 and 11 years old by the degree of processing and the nutritional profile. Nutrients. 2018;10(12):E1880. https:// doi.org/10.3390/nu10121880.

19. Aparicio A, Rodríguez-Rodríguez E, Cuadrado-Soto E, Navia B, López-Sobaler AM, Ortega RM. Estimation of salt intake assessed by urinary excretion of sodium over $24 \mathrm{~h}$ in Spanish subjects aged 7-11 years. Eur J Nutr. 2017; 56(1):171-8. https://doi.org/10.1007/s00394-015-1067-y.

20. World Health Organization (WHO) Expert Comitee. Physical status: The use and interpretation of anthropometry. Geneva; 1995.

21. Cole TJ, Lobstein T. Extended international (IOTF) body mass index cut-offs for thinness, overweight and obesity. Pediatr Obes. 2012;7(4):284-94. https:// doi.org/10.1111/j.2047-6310.2012.00064.x.

22. Ortega RM, López-Sobaler AM, Requejo Marcos AM. Cuestionario de actividad física. In: Requejo Marcos AM, Ortega Anta RM, editors. Nutriguía: manual of clinical nutrition in primary care. Madrid: Complutense Publisher; 2006

23. Ortega RM, Rodríguez-Rodríguez E, Aparicio A, et al. Poor zinc status is associated with increased risk of insulin resistance in Spanish children. $\mathrm{Br} J$ Nutr. 2012;107(3):398-404. https://doi.org/10.1017/S0007114511003114.

24. Rodríguez-Rodríguez E, López-Sobaler AM, Navia B, Andrés $P$, Jiménez Ortega Al, Ortega RM. $\beta$-Carotene concentration and its association with inflammatory biomarkers in Spanish schoolchildren. Ann Nutr Metab. 2017; 71(1-2):80-7. https://doi.org/10.1159/000479009.

25. González-Rodríguez LG, Aparicio A, López-Sobaler AM, Ortega RM. Omega 3 and omega 6 fatty acids intake and dietary sources in a representative sample of Spanish adults. Int J Vitam Nutr Res. 2013:83(1):36-47. https://doi. org/10.1024/0300-9831/a000143

26. National Research Council. Recommended Dietary Allowances. 10th ed. Washington: The National Academy Press; 1989. https://doi.org/10.17226/ 1349

27. World Health Organization (WHO). Global recommendations on physical activity for health. Geneva: WHO Library Cataloguing-in-Publication; 2010.

28. Tremblay MS, LeBlanc AG, Janssen I, et al. Canadian sedentary behaviour guidelines for children and youth. Appl Physiol Nutr Metab. 2011;36(1):5964. https://doi.org/10.1139/H11-012.

29. Institute of Medicine of the National Academies (IOM). Dietary Reference Intakes for Energy, Carbohydrate, Fiber, Fat, Fatty Acids, Cholesterol, Protein, and Amino Acids. Washintong D.C: The National Academies Press; 2005.

30. Ortega Anta RM, López-Sobaler AM, Aparicio Vizuete A, et al. ALADINO study 2015: study of surveillance of growth, diet, physical activity, child development and obesity in Spain 2015. Madrid; 2016.

31. Serra-Majem L, Aranceta Bartrina J, Pérez-Rodrigo C, Ribas-Barba L, DelgadoRubio A. Prevalence and deteminants of obesity in Spanish children and young people. Br J Nutr. 2006;96(Suppl 1):S67-72. https://doi.org/10.1079/ BJN20061703.

32. Morinigo Isla G, Sánchez Bernal S, Sispanov Pankow V, Brizuela Rivarola M, Rolón Villalba G, Mendoza de Arbo L. Nutritional profile of schoolchildren and adolescents in public and private schools, 2013. Pediatría. 2015;42(2): 129-33. https://doi.org/10.18004/ped.2015.agosto.129-133.

33. Mielgo-Ayuso J, Aparicio-Ugarriza R, Castillo A, et al. Physical activity patterns of the Spanish population are mostly determined by sex and age: findings in the ANIBES study. PLoS One. 2016;11(2):e0149969. https://doi. org/10.1371/journal.pone.0149969.

34. Zhu Z, Tang Y, Zhuang J, et al. Physical activity, screen viewing time, and overweight/obesity among Chinese children and adolescents: an update from the 2017 physical activity and fitness in China-the youth study. BMC Public Health. 2019;19(1):197. https://doi.org/10.1186/s12889-019-6515-9. 
35. Williamson C, Kelly P, Strain T. Different analysis methods of Scottish and English child physical activity data explain the majority of the difference between the national prevalence estimates. BMC Public Health. 2019;19(1): 171. https://doi.org/10.1186/s12889-019-6517-7.

36. Woods AM, Graber KC, Daum DN, Gentry C. Young school Children's recess physical activity: movement patterns and preferences. J Teach Phys Educ. 2015;34(3):496-516. https://doi.org/10.1123/jtpe.2014-0048.

37. Martínez-Andrés M, Bartolomé-Gutiérrez R, Rodríguez-Martín B, PardoGuijarro MJ, Martínez-Vizcaíno V. "Football is a boys game”: children's perceptions about barriers for physical activity during recess time. Int J Qual Stud Health Well-Being. 2017;12(1):1379338. https://doi.org/10.1080/ 17482631.2017.1379338.

38. Pizarro AN, Schipperijn J, Ribeiro JC, Figueiredo A, Mota J, Santos MP. Gender differences in the domain-specific contributions to MVPA, accessed by GPS. J Phys Act Health. 2017;14(6):474-8. 28253072. https://doi.org/10. 1123/jpah.2016-0346.

39. Telford RM, Telford RD, Olive LS, Cochrane T, Davey R. Why are girls less physically active than boys? Findings from the LOOK longitudinal study. PLoS One. 2016;11(3):e0150041. https://doi.org/10.1371/journal.pone. 0150041.

40. Yang F, Helgason AR, Sigfusdottir ID, Kristjansson AL. Electronic screen use and mental well-being of 10-12-year-old children. Eur J Pub Health. 2013; 23(3):492-8. https://doi.org/10.1093/eurpub/cks102.

41. Aoyama T, Tanaka S, Tanaka M, Okuda M, Inoue S, Tanaka C. Association between age at onset of independent walking and objectively measured sedentary behavior is mediated by moderate-to-vigorous physical activity in primary school children. PLoS One. 2018;13(9):e0204030. https://doi.org/10. 1371/journal.pone.0204030.

42. Sobal J, Milgrim M. Gendertyping sports: social representations of masculine, feminine, and neither-gendered sports among US university students. J Gend Stud. 2017;28(1):29-44. https://doi.org/10.1080/09589236. 2017.1386094.

43. Schmalz DL, Kerstetter DL. Girlie girls and manly men: Chidren's stigma consciousness of gender in sports and physical activities. J Leis Res. 2006; 38(4):536-57. https://doi.org/10.1080/00222216.2006.11950091.

44. Vandermeerschen $\mathrm{H}$, Vos S, Scheerder J. Who's joining the club? Participation of socially vulnerable children and adolescents in cluborganised sports. Sport Educ Soc. 2015;20(8):941-58. https://doi.org/10.1080/ 13573322.2013.856293.

45. Barraco GM, Martínez-Lozano N, Vales-Villamarín C, et al. Circadian health differs between boys and girls as assessed by non-invasive tools in schoolaged children. Clin Nutr. 2018;38(2):774-81. https://doi.org/10.1016/j.clnu. 2018.03 .001

46. National Sports Council of Spain (CSD). Sporting habits of the school population in Spain. Madrid, Spain; 2011.

47. Balish SM, Deaner RO, Rainham D, Blanchard C. Sex differences in sport remain when accounting for countries' gender inequality. Cross-Cultural Res. 2016;50(5):395-414. https://doi.org/10.1177/1069397116665815.

48. Mayeza E. 'Girls don't play soccer': children policing gender on the playground in a township primary school in South Africa. Gend Educ. 2017; 29(4):476-94. https://doi.org/10.1080/09540253.2016.1187262.

49. Paechter C, Clark S. Learning gender in primary school playgrounds: findings from the tomboy identities study. Pedagog Cult Soc. 2007;15(3): 317-31. https://doi.org/10.1080/14681360701602224.

50. Reimers AK, Schoeppe S, Demetriou Y, Knapp G. Physical activity and outdoor play of children in public playgrounds - do gender and social environment matter? Int J Environ Res Public Health. 2018;15(7). https://doi. org/10.3390/ijerph15071356.

51. Peplak J, Song JH, Colasante T, Malti T. "Only you can play with me!" Children's inclusive decision making, reasoning, and emotions based on peers' gender and behavior problems. J Exp Child Psychol. 2017;162:134-48. https://doi.org/10.1016/j.jecp.2017.04.019.

52. Fuemmeler BF, Anderson CB, Mâsse LC. Parent-child relationship of directly measured physical activity. Int J Behav Nutr Phys Act. 2011;8:17. https://doi. org/10.1186/1479-5868-8-17.

53. Hesketh KR, Brage S, Cooper C, et al. The association between maternalchild physical activity levels at the transition to formal schooling: crosssectional and prospective data from the Southampton Women's survey. Int J Behav Nutr Phys Act. 2019;16(1):23. https://doi.org/10.1186/s12966-0190782-9.
54. Johansson E, Mei H, Xiu L, et al. Physical activity in young children and their parents-an early STOPP Sweden-China comparison study. Sci Rep. 2016;6: 29595. https://doi.org/10.1038/srep29595.

55. Alberdi G, McNamara AE, Lindsay $\mathrm{KL}$, et al. The association between childcare and risk of childhood overweight and obesity in children aged 5 years and under: a systematic review. Eur J Pediatr. 2016;175(10):1277-94. https://doi.org/10.1007/s00431-016-2768-9.

56. Eli K, Howell K, Fisher PA, Nowicka P. A question of balance: explaining differences between parental and grandparental perspectives on preschoolers' feeding and physical activity. Soc Sci Med. 2016;154:28-35. https://doi.org/10.1016/j.socscimed.2016.02.030.

\section{Publisher's Note}

Springer Nature remains neutral with regard to jurisdictional claims in published maps and institutional affiliations.

\section{Ready to submit your research? Choose BMC and benefit from:}

- fast, convenient online submission

- thorough peer review by experienced researchers in your field

- rapid publication on acceptance

- support for research data, including large and complex data types

- gold Open Access which fosters wider collaboration and increased citations

- maximum visibility for your research: over $100 \mathrm{M}$ website views per year

At BMC, research is always in progress.

Learn more biomedcentral.com/submissions 